\title{
Trimetazidine protects against cardiac ischemia/reperfusion injury via effects on cardiac miRNA-21 expression, Akt and the Bcl-2/Bax pathway
}

\author{
NING MA ${ }^{1}$, JINGYUN BAI ${ }^{2}$, WEIHUA ZHANG ${ }^{1}$, HONG LUO $^{1}$, \\ XIN ZHANG $^{1}$, DONGHAI LIU ${ }^{1}$ and CHENHUI QIAO ${ }^{1}$ \\ Departments of ${ }^{1}$ Cardiovascular Surgery and ${ }^{2}$ Nephrology, The First Affiliated Hospital of Zhengzhou University, \\ Zhengzhou, Henan 450052, P.R. China
}

Received June 4, 2015; Accepted September 4, 2016

DOI: $10.3892 / \mathrm{mmr} .2016 .5773$

\begin{abstract}
Trimetazidine is a piperazine-derived metabolic agent, which exerts cell protective effects and has been reported to be efficient in the treatment of chronic stable angina pectoris. In addition, it has been shown to exert protection against acute myocardial infarction. The present study aimed to investigate whether trimetazidine protects against cardiac ischemia/reperfusion (I/R) injury, and to determine whether its curative effects are associated with microRNA (miRNA)-21 expression, Akt, and the B-cell lymphoma 2 (Bcl-2)/Bcl-2-associated X protein (Bax) pathway. Cardiac $\mathrm{I} / \mathrm{R}$ injury was induced by ligating the left anterior descending coronary artery in adult rats. Subsequently, cardiac function was evaluated, and the expression levels of miRNA-21, Bcl-2, Bax and phosphorylated-Akt were detected using quantitative polymerase chain reaction and western blotting. The results indicated that trimetazidine was able to significantly protect cardiac function and reduce infarct size in rats following cardiac I/R injury. Furthermore, trimetazidine significantly promoted miRNA-21 expression and phosphorylated-Akt protein expression, and reduced the $\mathrm{Bcl}-2 / \mathrm{Bax}$ ratio in rats following cardiac I/R injury. Knockdown of miRNA-21 using anti-miR-21 plasmids was able to reverse the protective effects of trimetazidine against cardiac I/R injury. These results indicated that miRNA-21 serves a protective role in cardiac $\mathrm{I} / \mathrm{R}$ injury via Akt and the Bcl-2/Bax pathway. In addition, trimetazidine exerts protective effects against cardiac I/R injury through cardiac miRNA-21 expression, Akt, and the Bcl-2/Bax pathway. Therefore, the present study provided
\end{abstract}

Correspondence to: Mr. Chenhui Qiao, Department of Cardiovascular Surgery, The First Affiliated Hospital of Zhengzhou University, 1 Jianshe East Road, Zhengzhou, Henan 450052, P.R. China

E-mail: chenhuiqiaoqq@163.com

Key words: trimetazidine, cardiac ischemia/reperfusion injury, microRNA-21, Akt, Bcl-2/Bax evidence regarding the protective effects of miRNA-21 on cardiac I/R injury following treatment with trimetazidine in vivo.

\section{Introduction}

Cardiac ischemia/reperfusion (I/R) injury is a serious disease that threatens human health (1). It may occur following various procedures in which myocardial blood supply to an ischemic region is reestablished, including treatment of thrombolysis, percutaneous coronary angioplasty or coronary artery bypass grafting (2). The subsequent reperfusion that occurs through the epicardial coronary arteries following these treatments does not ensure achievement of complete myocardial reperfusion and recovery of the normal internal environment, and cardiac I/R injury may occur (3). Serious myocardial damage-induced ventricular remodeling, deterioration of cardiac function, development of congestive heart failure and mortality may occur following cardiac I/R injury (4). Myocardial necrosis, apoptosis and ventricular remodeling due to cardiac I/R injury are the predominant pathological features of reperfusion-induced cardiac dysfunction following treatment. Therefore, it is important to prevent ventricular remodeling following cardiac I/R injury (5). The expression of certain genes may be dysregulated in cardiac cells following cardiac I/R injury, thus resulting in the altered expression of corresponding proteins; these effects may be the pathological basis of injury remodeling in cardiac I/R injury. Therefore, studying ventricular remodeling at the genetic level may provide novel strategies for the clinical treatment of ventricular remodeling following I/R injury (6).

MicroRNAs (miRNAs) are non-coding small eukaryotic RNAs ( 18-22 bp), which exert endogenous regulatory functions and are highly conserved. miRNAs have a close association with several types of heart disease (7). Previous studies reported that, through the use of chip technology on samples from a mouse model of myocardial hypertrophy and human beings with heart disease, several miRNAs (miRNA-1, $-21,-133,-195,-214)$ are significantly upregulated compared with in control samples; therefore, overexpression or inhibition of some miRNAs (miRNA-1, -133, -195, -208 and -214) 
may exert a significant influence on heart growth, myocardial hypertrophy and ventricular remodeling $(8,9)$.

Trimetazidine is a drug that directly stimulates the myocardium and indirectly promotes myocardial glucose metabolism. It reduces the demand for oxygen during high-energy phosphate generation, decreases oxygen consumption during the production of ATP, and increases oxygen utilization efficiency during myocardial hypoxia (10). Compared with traditional anti-ischemic drugs, trimetazidine is a drug with a unique mechanism of action, since it exerts direct effects on myocardial ischemia without inducing hemodynamic changes (11). Furthermore, the present study aimed to investigate whether trimetazidine may protect against cardiac I/R injury, and to determine whether its curative effects may be associated with miRNA-21 expression, Akt, and the Bcl-2/Bax pathway.

\section{Materials and methods}

Animals and experimental protocols. Adult male Sprague-Dawley rats (age, 10-11 weeks; weight, 250-300 g) were purchased from the Laboratory Animal Center of Zhengzhou University (Zhengzhou, China) and were maintained in cages at room temperature $\left(23 \pm 2^{\circ} \mathrm{C}\right)$, under a $12 \mathrm{~h}$ light-dark cycle, with constant humidity $(55 \pm 5 \%)$. The rats had ad libitum access to food and water. All animal protocols were performed in accordance with the National Institutes of Health Guide for the Care and Use of Laboratory Animals (2014). The present study was approved by the Ethics Committee of Life Science of Zhengzhou University. The rats were randomized into four groups: i) The control group $(n=24)$, in which normal rats were administered saline alone $(0.1 \mathrm{ml} / 100 \mathrm{~g}$, i.p. $)$ for 5 days; ii) the control-trimetazidine group $(n=25)$, in which normal rats received trimetazidine (30 mg/kg; Sigma-Aldrich; Merck Millipore, Darmstadt, Germany) for 5 days; iii) the cardiac I/R injury model group $(n=25)$, rats received saline following induction of cardiac I/R injury $(0.1 \mathrm{ml} / 100 \mathrm{~g}$, i.p.) for 5 days; and iv) the trimetazidine treatment group $(n=25)$, rats received trimetazidine following cardiac I/R injury (30 mg/kg) for 5 days.

Cardiac I/R injury model establishment. Briefly, rats were anesthetized with pentobarbital sodium (50 mg/ $\mathrm{kg}$, i.p.), placed in a supine position, intubated, and artificially ventilated using a respirator. All surgical procedures were executed under aseptic conditions. The hearts of the rats were exposed following an incision into the fourth intercostal space on the left side of the chest. The left anterior descending coronary artery was ligated with 6-0 silk suture using a snare occluder. Cardiac ischemia was confirmed by visual observation and continuous electrocardiogram monitoring. Following $40 \mathrm{~min}$ of occlusion, the coronary artery was reperfused by releasing the knot. The hearts of the rats were harvested following 180 min reperfusion. Rats in the control group underwent chest incision without ligation. Subsequently, rats were anesthetized with pentobarbital sodium (50 mg/kg, i.p.) and were sacrificed by decapitation.

Measurement of casein kinase (CK) and lactate dehydrogenase $(\mathrm{LDH})$ levels. Briefly, whole blood samples were extracted from the vena cava following treatment with trimetazidine or saline. Subsequently, the serum samples were acquired following centrifugation of the blood samples at 3,000 $\mathrm{x} g$ for $10 \mathrm{~min}$ at $4^{\circ} \mathrm{C}$. The supernatant was considered the serum, which was maintained at $-80^{\circ} \mathrm{C}$ until further use. CK (cat. no. A032) and LDH (cat. no. A020-1) activities were determined using a series of commercial kits, according to the manufacture's protocols (Sangon Biotech Co., Ltd., Shanghai, China).

Determination of infarct size. Briefly, the rat hearts were injected with Evans Blue solution (1.5\%; Sigma-Aldrich; Merck Millipore) and were immediately separated following treatment with trimetazidine or saline. Subsequently, the hearts were sliced into $2 \mathrm{~mm}$ sections for infarct size measurement. Infarct size was determined following staining with 2,3,5-triphenyltetrazolium chloride $(1.5 \%)$ at $37^{\circ} \mathrm{C}$ for $30 \mathrm{~min}$ in the dark $(12,13)$. After staining, the sections were fixed by immersion in $4 \%$ paraformaldehyde solution. The area of the heart without color was regarded as ischemic myocardium, whereas the area stained brick red was regarded as normal myocardium.

Cell culture. H9c2 adult rat ventricular myocyte cells (Shanghai Cell Bank of Chinese Academy of Sciences, Shanghai, China) were cultured in Dulbecco's modified Eagle's medium (DMEM) medium (Sigma-Aldrich; Merck Millipore) supplemented with $10 \%$ fetal bovine serum (FBS; Invitrogen; Thermo Fisher Scientific, Inc.) at $37^{\circ} \mathrm{C}$ in a humidified atmosphere containing 5\% $\mathrm{CO}_{2}$. Medium was refreshed every 2-3 days. For oxygen-glucose deprivation-treated cells, H9c2 cells were incubated with DMEM without glucose in a humidified atmosphere containing $5 \% \mathrm{CO}_{2}$ and $95 \% \mathrm{~N}_{2}(\mathrm{v} / \mathrm{v})$ at $37^{\circ} \mathrm{C}$ for $10 \mathrm{~h}$. Following hypoxia, the culture medium was removed, and fresh high glucose DMEM containing 10\% FBS was added to H9c2 cells in a regular $5 \% \mathrm{CO}_{2}$ incubator.

Transfection and treatment. Negative control miRNA (miR-NC) and anti-miR-21 plasmids were designed and purchased by Sangon Biotech Co., Ltd. The sequences were as follows: Anti-miR-21, 5'-UCAACAUCAGUCUGAUAAGCUA-3'; and miR-NC, 5'-CAGUACUUUUGUGUAGUACAA-3'. The $\mathrm{H} 9 \mathrm{c} 2$ cells were divided into three groups: Control group, in which cells were transfected with miR-NC plasmids for $48 \mathrm{~h}$; trimetazidine group, in which cells were treated with $10 \mu \mathrm{M}$ trimetazidine for $48 \mathrm{~h}$; and anti-miR-21 group, in which cells were transfected with anti-miR-21 plasmids for $24 \mathrm{~h}$ and were then treated with $10 \mu \mathrm{M}$ trimetazidine for $48 \mathrm{~h}$. The plasmids were transfected into H9c2 cells using Lipofectamine 2000 (Invitrogen; Thermo Fisher Scientific, Inc.) according to the manufacturer's protocol.

Quantitative polymerase chain reaction ( $q P C R$ ) assay of $m i R N A-21$. Rats were anesthetized with pentobarbital sodium $(50 \mathrm{mg} / \mathrm{kg}$, i.p.) and were sacrificed by decapitation. Subsequently, heart tissues were obtained from the pericardium and were washed with phosphate-buffered saline. miRNA-21 expression was detected in heart tissue samples or H9c2 cells following RNA extraction using TRIzol reagent (Invitrogen; Thermo Fisher Scientific, Inc., Waltham, MA, USA), according to the manufacturer's protocol. cDNA was generated from total RNA $(1 \mu \mathrm{g})$ using the Superscript First-Strand Synthesis system (Invitrogen; Thermo Fisher Scientific, Inc.) at $37^{\circ} \mathrm{C}$ for $60 \mathrm{~min}$ and $85^{\circ} \mathrm{C}$ for $60 \mathrm{sec}$. The primers used in the present study were as follows: miR-21, 
forward 5'-GGGGGTACCCTTCAGGAAGCTGGTTTC-3', reverse 5'-GGGGATATCTACATGTGAGGCAGGTTCT CAC-3'; and U6, forward 5'-CGCTTCGGCACATATACT A-3' and reverse 5'-CGCTTCACGAATTTGCGTGTC A-3' (Sangon Biotech Co., Ltd.). qPCR detection of miR-21 expression was performed on a 7300 Sequence Detection system (Applied Biosystems; Thermo Fisher Scientific, Inc.) using the TaqMan MicroRNA Assay kit (Invitrogen; Thermo Fisher Scientific, Inc.), according to the manufacturer's protocols. The PCR cycling conditions were as follows: $94^{\circ} \mathrm{C}$ for $60 \mathrm{sec}$, followed by 40 cycles at $95^{\circ} \mathrm{C}$ for $15 \mathrm{sec}, 60^{\circ} \mathrm{C}$ for $30 \mathrm{sec}$ and $72^{\circ} \mathrm{C}$ for $15 \mathrm{sec}$. The expression levels of miR-21 were normalized to $\mathrm{U} 6$, and the levels were quantified using the $2^{-\Delta \Delta \mathrm{Cq}}$ method (14).

Western blot analysis. Briefly, the hearts were rapidly removed and homogenized in $1 \mathrm{ml}$ modified tonic sucrose solution, following treatment with trimetazidine or saline. Total protein was extracted from heart tissues and cells using radioimmunoprecipitation assay buffer (Beyotime Institute of Biotechnology, Shanghai, China). Following centrifugation at $12,000 \mathrm{x} g$ for $10 \mathrm{~min}$ at $4^{\circ} \mathrm{C}$, the protein concentration was determined using a Bicinchoninic Acid protein assay (Beyotime Institute of Biotechnology). Protein samples (50-60 $\mu \mathrm{g})$ were separated by 8-12\% sodium dodecyl sulfate-polyacrylamide gel electrophoresis and were electrophoretically transferred to polyvinylidene fluoride membranes (EMD Millipore, Billerica, MA, USA, $0.22 \mathrm{~mm}$ ). Subsequently, the membranes were washed with Tris-buffered saline containing 5\% nonfat milk for $1 \mathrm{~h}$ at $37^{\circ} \mathrm{C}$. The blocked membranes were then incubated with the following antibodies: Anti-phosphorylated (p)-Akt (cat. no. sc-135650; 1:2,000; Santa Cruz Biotechnology, Inc., Dallas, TX, USA), anti-B-cell lymphoma 2 (Bcl-2; cat. no. sc-492; 1:1,000; Santa Cruz Biotechnology, Inc.), anti-Bcl-2-associated X protein (Bax; cat. no. sc-6236; 1:1,000; Santa Cruz Biotechnology, Inc.) and anti- $\beta$-actin (1:500; cat. no. D110007; Sangon Biotech Co., Ltd.) overnight at $4^{\circ} \mathrm{C}$. The membranes were then probed with an anti-rabbit horseradish peroxidase-conjugated immunoglobulin G secondary antibody (1:5,000; cat. no. sc-2054; Santa Cruz Biotechnology, Inc.) at $37^{\circ} \mathrm{C}$ for $1 \mathrm{~h}$. Protein bands were visualized using a highly sensitive enhanced chemiluminescence reagent (cat. no. C500044, Sangon Biotech Co., Ltd.) and were quantified by Odyssey v1.2 software (LI-COR Biosciences, Lincoln, NE, USA).

Statistical analysis. Results were analyzed using SPSS 19.0 statistical software (IBM SPSS, Armonk, NY, USA) and are presented as the mean \pm standard error of the mean. The differences between more than two groups were analyzed using analysis of variance followed by Tukey's honest significant difference test. All experiments were repeated three times. $\mathrm{P}<0.05$ was considered to indicate a statistically significant difference.

\section{Results}

Trimetazidine protects cardiac function. The chemical structure of trimetazidine is presented in Fig. 1. In the present study trimetazidine (97\% purity) was dissolved in physiological saline. The present study aimed to determine the potential protective effects of trimetazidine on cardiac function following cardiac I/R injury. I/R injury effectively increased $\mathrm{CK}$ and $\mathrm{LDH}$ activities compared with the control group (Fig. 2; $\mathrm{P}=0.0023$ and $\mathrm{P}=0.0043$ ). However, trimetazidine markedly reduced $\mathrm{CK}$ and $\mathrm{LDH}$ activities in rats following $\mathrm{I} / \mathrm{R}$ injury (Fig. 2; $\mathrm{P}=0.0031$ and $\mathrm{P}=0.0059$ ).

Trimetazidine reduces infarct size. The present study aimed to determine whether the potential protective effects of trimetazidine reduced infarct size following cardiac I/R injury. As shown in Fig. 3, compared with the control group, the infarct size was markedly increased in rats following cardiac $I / R$ injury $(\mathrm{P}=0.0056)$. However, treatment with trimetazidine markedly reduced infarct size following cardiac I/R injury (Fig. 3; $\mathrm{P}=0.0077$ ).

Trimetazidine activates miRNA-21 expression. To investigate the potential effects of trimetazidine on cardiac I/R injury, miRNA-21 expression was detected using qPCR. As shown in Fig. 4, cardiac I/R injury markedly suppressed miRNA-21 expression in rats, as compared with in the control group (Fig. 4; $\mathrm{P}=0.0009$ ). Conversely, the protective effects of trimetazidine markedly upregulated miRNA-21 expression following cardiac I/R injury (Fig. 4; $\mathrm{P}=0.0016$ ).

Trimetazidine activates Akt protein expression. To determine the potential effects of trimetazidine on cardiac $I / R$ injury, p-Akt protein expression was detected using western blot analysis. As shown in Fig. 5A and B, cardiac I/R injury significantly suppressed p-Akt protein expression in rats compared with the control group $(\mathrm{P}=0.0014)$. However, the protective effects of trimetazidine significantly increased p-Akt protein expression in rats following cardiac I/R injury (Fig. 5A and $\mathrm{B} ; \mathrm{P}=0.0031$ ).

Trimetazidine suppresses Bcl-2/Bax protein expressions. To explore the potential involvement of trimetazidine in cardiac I/R injury, Bcl-2/Bax protein expression was detected using western blot analysis. Cardiac I/R injury significantly suppressed $\mathrm{Bcl}-2$ protein expression and promoted Bax protein expression in rats, as compared with in the control group (Fig. 6A-D). Conversely, the protective effects of trimetazidine significantly reversed Bcl-2 and Bax protein expression levels in rats following cardiac $\mathrm{I} / \mathrm{R}$ injury (Fig. 6A-D; $\mathrm{P}=0.0011$ ).

Knockdown of cardiac miRNA-21 expression affects the protective effect of trimetazidine. To further investigate the biological involvement of miRNA-21 in trimetazidine-mediated cardiac protection, miR-NC and anti-miR-21 plasmids were transfected into H9c2 cells using Lipofectamine 2000. Transfection with anti-miR-21 plasmid significantly decreased miRNA-21 expression in anoxia-induced $\mathrm{H} 9 \mathrm{c} 2$ cells, as compared with in the control group (Fig. 7A; $\mathrm{P}=0.0032$ ). Furthermore, the $\mathrm{CK}$ and LDH activities of anoxia-induced H9c2 cells were markedly suppressed following treatment with trimetazidine compared with the control group (Fig. 7B and $\mathrm{C} ; \mathrm{P}=0.0061$ and $\mathrm{P}=0.0042$ ). Conversely, transfection with the anti-miR-21 plasmid markedly increased the $\mathrm{CK}$ and $\mathrm{LDH}$ activities of anoxia-induced $\mathrm{H} 9 \mathrm{c} 2$ cells (Fig. 7B and $\mathrm{C} ; \mathrm{P}=0.0082$ and $\mathrm{P}=0.0058$ ). 


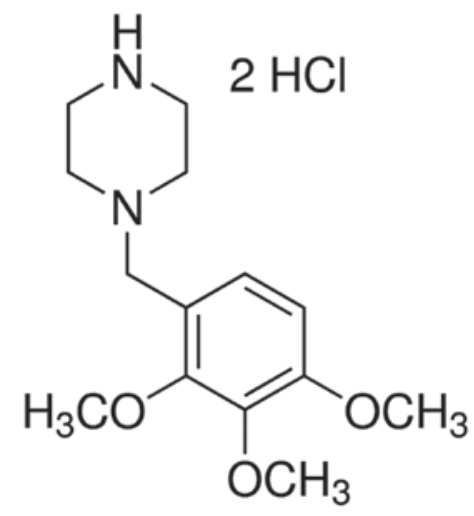

Figure 1. Chemical structure of trimetazidine.

Knockdown of cardiac miRNA-21 expression affects p-Akt protein expression. To further explore the mechanism underlying trimetazidine-induced miRNA-21-mediated cardiac protection in vivo, the effects of cardiac miRNA-21 expression knockdown on p-Akt protein expression were detected. The protein expression levels of p-Akt in anoxia-induced H9c2 cells were markedly elevated following treatment with trimetazidine compared with the control group (Fig. 8A and $\mathrm{B} ; \mathrm{P}=0.0027)$. Notably, knockdown of cardiac miRNA-21 expression significantly reduced $\mathrm{p}$-Akt protein expression in anoxia-induced H9c2 cells (Fig. 8A and B; $\mathrm{P}=0.0047$ ).

Knockdown of cardiac miRNA-21 expression affects Bcl-2/Bax protein expression. To further analyze the mechanism underlying trimetazidine-induced miRNA-21-mediated cardiac protection in vivo, the effects of cardiac miRNA-21 expression knockdown on Bcl-2/Bax protein expression were detected. As shown in Fig. 9A and B, treatment with trimetazidine markedly increased $\mathrm{Bcl}-2$ protein expression in anoxia-induced $\mathrm{H} 9 \mathrm{c} 2$ cells compared with in the control group ( $\mathrm{P}=0.0013)$. However, knockdown of cardiac miRNA-21 expression significantly inhibited $\mathrm{Bcl}-2$ protein expression in anoxia-induced H9c2 cells (Fig. 9A and B; $\mathrm{P}=0.0026)$. Furthermore, treatment with trimetazidine markedly reduced Bax protein expression in anoxia-induced H9c2 cells, compared with the control group (Fig. 9C and $\mathrm{D} ; \mathrm{P}=0.0025$ ). Conversely, knockdown of cardiac miRNA-21 expression significantly augmented Bax protein expression in anoxia-induced H9c2 cells (Fig. 9C and D; $\mathrm{P}=0.0047$ ).

\section{Discussion}

Cardiac I/R injury refers to a series of myocardial episodes that are caused by coronary recanalization and myocardial reperfusion after myocardial ischemia. I/R injury induces complex physiological and pathological alterations (15). Following myocardial ischemia, due to cardiac ischemia, hypoxia and damage to the myocardial cell membranes, cardiac cells exhibit a reduced energy supply, cell membrane permeability is increased, dysfunction of the membrane pump occurs, the ability of the cell to regulate intracellular $\mathrm{Ca}^{2+}$ levels is lost, and the cells undergo degeneration or necrosis. In addition, $\mathrm{LDH}$, $\mathrm{CK}$ and other enzymes leak from the cells resulting in increased serum concentrations (16). The increased degree of enzymatic
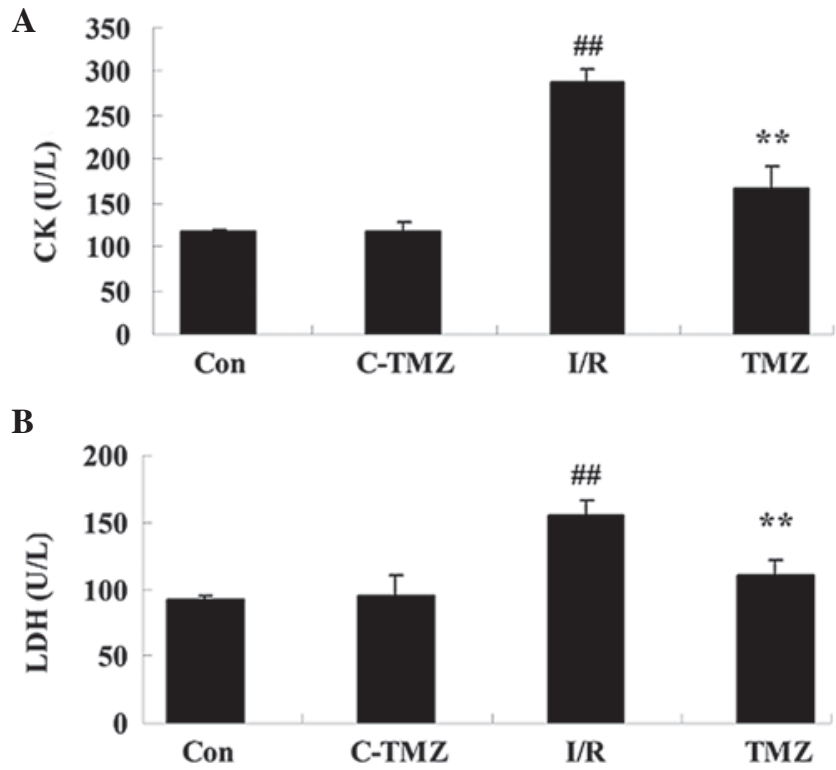

Figure 2. Trimetazidine protects cardiac function. Trimetazidine exerts protective effects against (A) CK and (B) LDH activities in rats following cardiac I/R injury. ${ }^{\# \#} \mathrm{P}<0.05$ vs. control group; ${ }^{* *} \mathrm{P}<0.05$ vs. I/R group. Con, control group; C-TMZ, control-trimetazidine group; I/R, cardiac ischemia/reperfusion injury model group; TMZ, trimetazidine $(30 \mathrm{mg} / \mathrm{kg})$ treatment group; $\mathrm{CK}$, casein kinase; $\mathrm{LDH}$, lactate dehydrogenase.

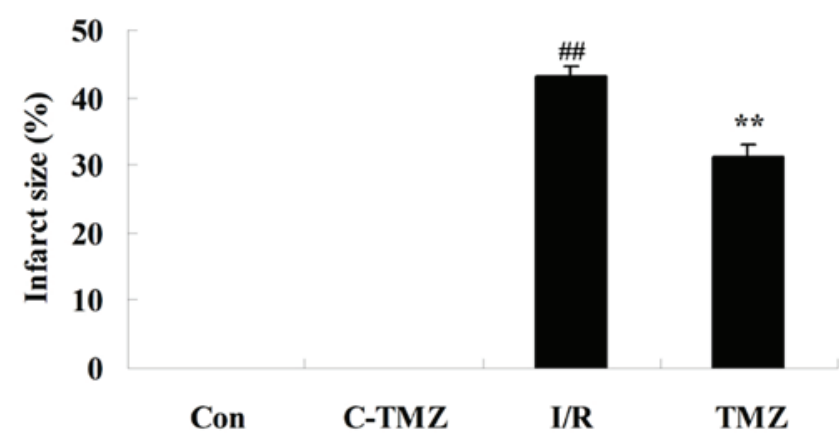

Figure 3. Trimetazidine reduces infarct size. ${ }^{\# \#} \mathrm{P}<0.05$ vs. control group; ${ }^{* *} \mathrm{P}<0.05$ vs. I/R group. Con, control group; C-TMZ, control-trimetazidine group; I/R, cardiac ischemia/reperfusion injury model group; TMZ, trimetazidine $(30 \mathrm{mg} / \mathrm{kg})$ treatment group.

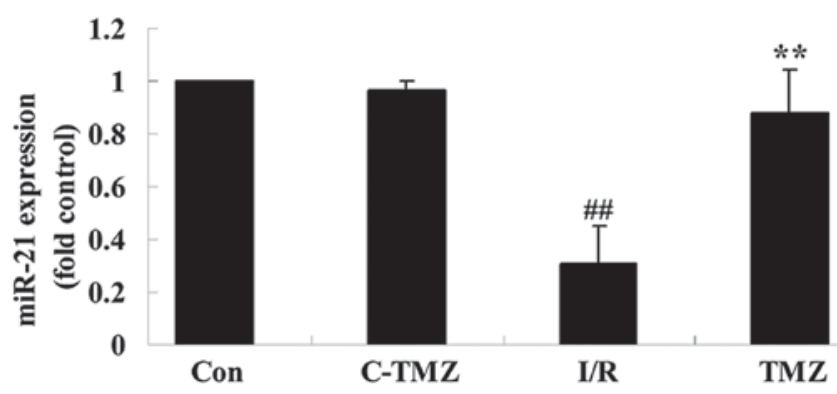

Figure 4. Trimetazidine activates miRNA-21 expression. ${ }^{\# \prime} \mathrm{P}<0.05$ vs. control group; ${ }^{* *} \mathrm{P}<0.05$ vs. I/R group. Con, control group; C-TMZ, control-trimetazidine group; I/R, cardiac ischemia/reperfusion injury model group; TMZ, trimetazidine $(30 \mathrm{mg} / \mathrm{kg})$ treatment group; miRNA/miR-21, microRNA-21.

activity in the serum can reflect the extent of myocardial damage (17). The results of the present study indicated that the 
A

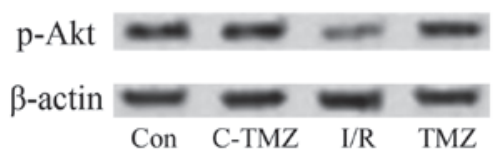

B

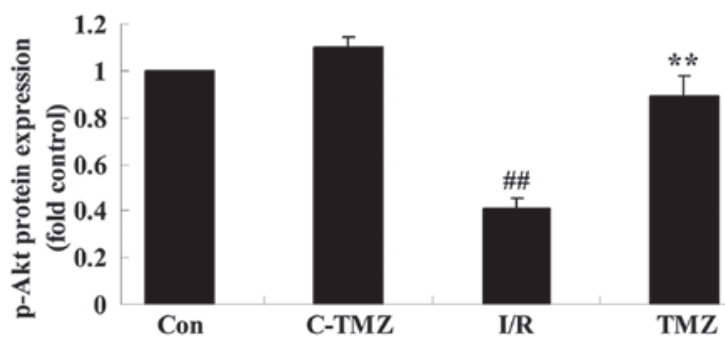

Figure 5. Trimetazidine activates Akt protein expression. P-Akt protein expression was detected in rats following cardiac I/R injury (A) using western blotting, and (B) the results were statistically analyzed. ${ }^{\# \#} \mathrm{P}<0.05$ vs. control group; ${ }^{* *} \mathrm{P}<0.05$ vs. I/R group. Con, control group; C-TMZ, control-trimetazidine group; I/R, cardiac ischemia/reperfusion injury model group; TMZ, trimetazidine $(30 \mathrm{mg} / \mathrm{kg})$ treatment group; $\mathrm{p}$-, phosphorylated.

A

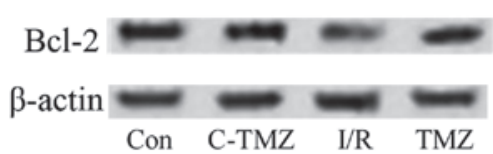

C

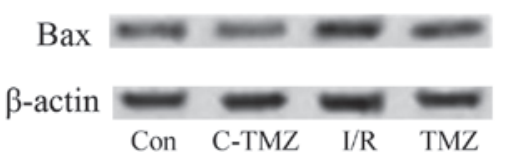

D
B
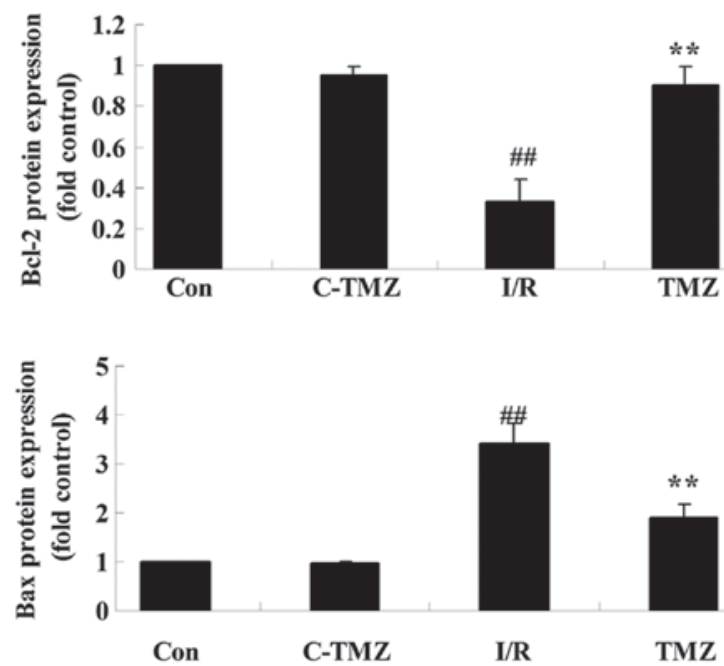

Figure 6. Trimetazidine suppresses Bcl-2/Bax protein expression. (A and B) Bcl-2 and (C and D) Bax protein expression levels were detected following cardiac $\mathrm{I} / \mathrm{R}$ injury using (A and $\mathrm{C}$ ) western blotting, and (B and $\mathrm{D})$ the results were statistically analyzed. ${ }^{\# \#} \mathrm{P}<0.05$ vs. control group; ${ }^{* *} \mathrm{P}<0.05$ vs. I/R group. Con, control group; C-TMZ, control-trimetazidine group; I/R, cardiac ischemia/reperfusion injury model group; TMZ, trimetazidine (30 mg/kg) treatment group; Bcl-2, B-cell lymphoma 2; Bax, Bcl-2-associated X protein.
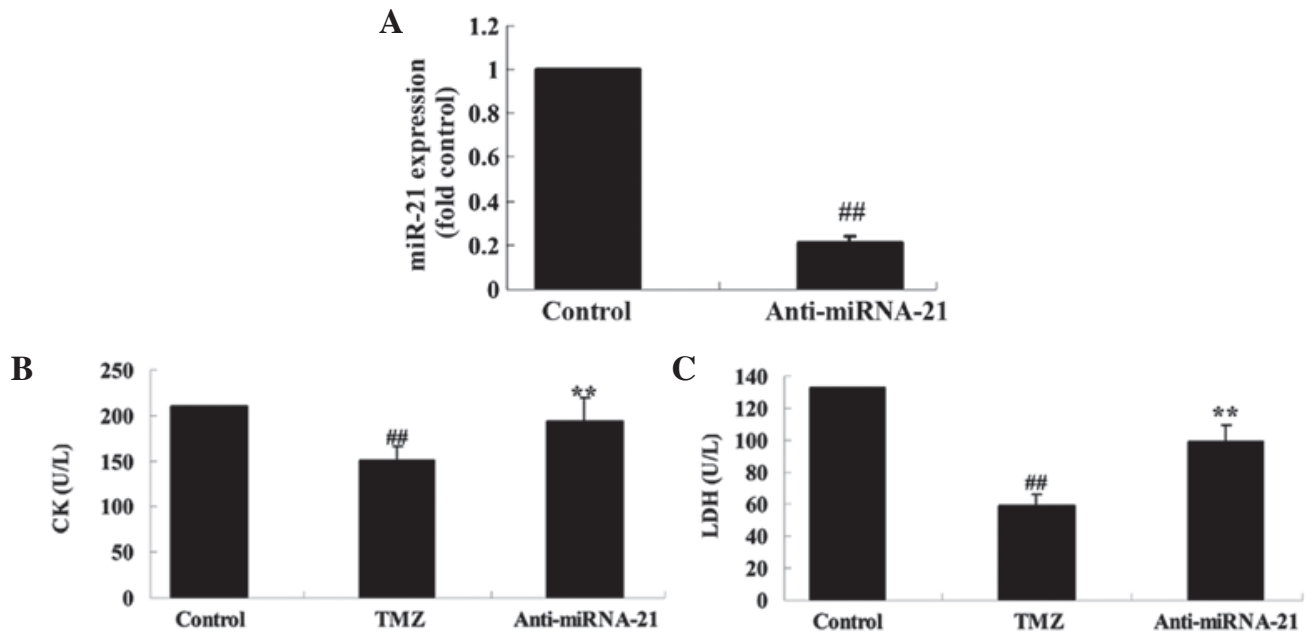

Figure 7. Knockdown of cardiac miRNA-21 expression affects the protective effect of trimetazidine. Knockdown of cardiac miRNA-21 expression affects (A) miRNA-21 expression, and the protective effects of trimetazidine against (B) CK and (C) LDH activities in anoxia-induced $\mathrm{H} 9 \mathrm{c} 2$ cells. ${ }^{\# / P}<0.05$ vs. control group; " ${ }^{*}<0.05$ vs. TMZ group. Control, miR-NC-transfected group; TMZ, trimetazidine treatment group; anti-miRNA-21, anti-miRNA-21-transfected group; CK, casein kinase; LDH, lactate dehydrogenase; miRNA/miR-21, microRNA-21.

potential protective effects of trimetazidine effectively reduced these alterations in rats following I/R injury. Ussher et al reported that treatment with trimetazidine may prevent obesity-induced cardiomyopathy in mice (18). Furthermore, Allibardi et al demonstrated that trimetazidine induces metabolic and functional recovery in post-ischemic rat hearts (19). 

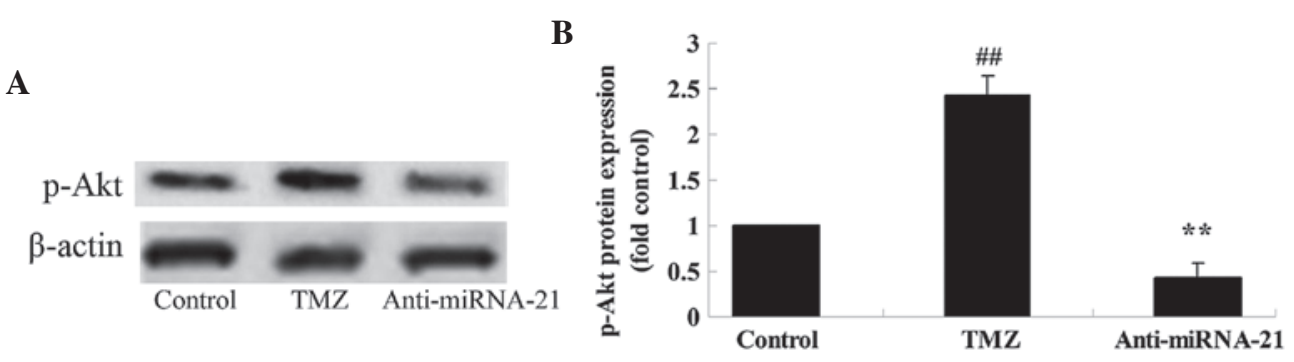

Figure 8. Knockdown of cardiac miR-21 expression affects p-Akt protein expression. (A) P-Akt protein expression was detected following miRNA-21 knockdown in anoxia-induced $\mathrm{H} 9 \mathrm{c} 2$ cells using western blotting, and (B) the results were statistically analyzed. ${ }^{\# \#} \mathrm{P}<0.05$ vs. control group; ${ }^{* *} \mathrm{P}<0.05$ vs. TMZ group. Control, miR-NC-transfected group; TMZ, trimetazidine treatment group; anti-miRNA-21, anti-miRNA-21-transfected group; miRNA-21, microRNA-21; p-, phosphorylated.

A

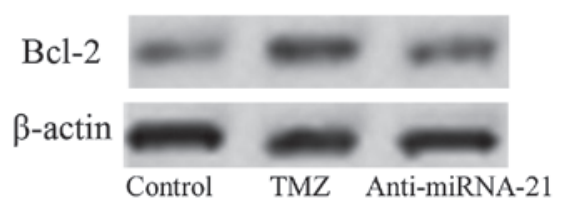

C

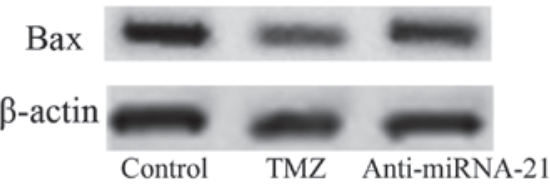

B

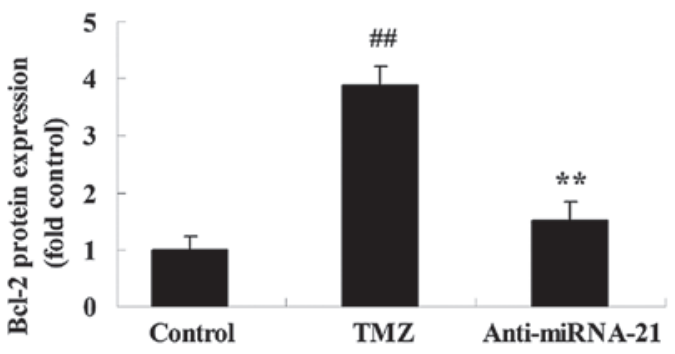

D

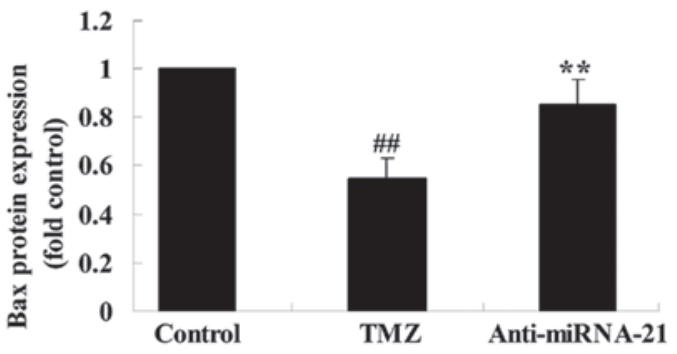

Figure 9. Knockdown of cardiac miRNA-21 expression affects on Bcl-2/Bax protein expression. (A and B) Bcl-2 and (C and D) Bax protein expression levels were detected following miRNA-21 knockdown in anoxia-induced H9c2 cells (A and C) using western blotting, and (B and D) the results were statistically analyzed. ${ }^{\# \#} \mathrm{P}<0.05$ vs. control group; ${ }^{* *} \mathrm{P}<0.05$ vs. TMZ group. Control, miR-NC-transfected group; TMZ, trimetazidine treatment group; anti-miRNA-21, anti-miRNA-21-transfected group; miRNA-21, microRNA-21; Bcl-2, B-cell lymphoma 2; Bax, Bcl-2-associated X protein.

Previous studies demonstrated that heat shock and ischemic preconditioning can induce miRNA-1, -21 and -24 expression in heart tissue, which affects the expression of endothelial nitric oxide synthase and heat shock protein 70 , resulting in decreased I/R injury after $24 \mathrm{~h}(20-22)$. miRNA-21 is an anti-apoptotic gene that has an important role in the mechanism of anti-apoptosis and the regulation of programmed cell death factor 4 (PDCD4). In addition, miRNA-21 is able to reduce myocardial cell death after $\mathrm{H}_{2} \mathrm{O}_{2}$ stimulation via regulation of PDCD4 (23). Furthermore, myocardial ischemia may induce damage to myocardial cells via miRNA expression (24). It is well-known that miRNA in myocardial tissues has a role in the preliminary stage of myocardial ischemia. It is of great significance to further study the regulatory mechanisms of miRNA in cardiac I/R injury. In the present study, the protective effects of trimetazidine significantly promoted the expression of miRNA-21 in rats following cardiac I/R injury. In a recent study, Liu et al reported that trimetazidine improves right ventricular function via the upregulation of miR-21 expression (8).

Apoptosis is a genetically programmed form of cell death. Akt has a key role in preventing apoptosis, and the regulation of glucose metabolism and protein synthesis (25). The isolated hearts from a rat model of ischemic pretreatment exhibited significantly increased levels of Akt phosphorylation and reduced myocardial infarction; however, administration of the phosphoinositide 3-kinase suppressor LY-294002 inhibited the myocardial protective effects of ischemic preconditioning (26). In the present study, the protective effects of trimetazidine significantly increased the expression of p-Akt in rats following cardiac I/R injury. It has previously been demonstrated that the protective effects of trimetazidine significantly enhanced heart function recovery via Akt activation (27).

Apoptosis is a genetically programmed form of cell death. Bcl-2 exerts an inhibitory function on apoptosis. Bcl-2 and Bax proteins are the two main members of the Bcl-2 multi-gene family (28). Bcl-2 inhibits apoptosis, whereas Bax exerts a proapoptotic effect. In rat cardiac I/R injury, increased expression of the anti-apoptosis gene Bcl-2 in the myocardium and reduced expression of Bax may reduce cardiac I/R injury (29). The present study demonstrated that trimetazidine significantly augmented the Bcl-2/Bax ratio in rats following cardiac I/R injury. Furthermore, Khan et al demonstrated that trimetazidine ameliorates myocardial dysfunction and injury via activation of Akt signaling (30). To further analyze the mechanism 
underlying trimetazidine-induced miRNA-21-mediated cardiac protection in vivo, the effects of cardiac miRNA-21 expression knockdown on Bcl-2/Bax protein expression were detected. The results confirmed that silencing miRNA-21 expression reversed the protective effects of trimetazidine against cardiac I/R injury via suppression of $\mathrm{p}-\mathrm{Akt}$ and the $\mathrm{Bcl}-2 / \mathrm{Bax}$ pathway.

In conclusion, the present study demonstrated that trimetazidine protects against cardiac I/R injury in vitro. The findings indicated that miR-21 contributes to the protective effect of trimetazidine against cardiac $\mathrm{I} / \mathrm{R}$ injury via Akt and the Bcl-2/Bax pathway. The results of the present study may help to provide a rational novel drug for the treatment of cardiac I/R injury.

\section{References}

1. Xiao J, Li J, Xu T, Lv D, Shen B, Song Y and Xu J: Pregnancy-induced physiological hypertrophy protects against cardiac ischemia-reperfusion injury. Int J Clin Exp Pathol 7: 229-235, 2013

2. Pisarenko OI, Lankin VZ, Konovalova GG, Serebryakova LI, Shulzhenko VS, Timoshin AA, Tskitishvili OV, Pelogeykina YA and Studneva IM: Apelin-12 and its structural analog enhance antioxidant defense in experimental myocardial ischemia and reperfusion. Mol Cell Biochem 391: 241-250, 2014.

3. Liu LF, Qin Q, Qian ZH, Shi M, Deng QC, Zhu WP Zhang H, Tao XM and Liu Y: Protective effects of melatonin on ischemia-reperfusion induced myocardial damage and hemodynamic recovery in rats. Eur Rev Med Pharmacol Sci 18 3681-3686, 2014

4. Lenčová-Popelová O, Jirkovský E, Mazurová Y, Lenčo J, Adamcová M, Šimůnek T, Geršl V and Štěrba M: Molecular remodeling of left and right ventricular myocardium in chronic anthracycline cardiotoxicity and post-treatment follow up. PLoS One 9: e96055, 2014

5. Chua CC, Gao J, Ho YS, Xu X, Kuo IC, Chua KY, Wang H, Hamdy RC, Reed JC and Chua BH: Over-expression of a modified bifunctional apoptosis regulator protects against cardiac injury and doxorubicin-induced cardiotoxicity in transgenic mice. Cardiovasc Res 81: 20-27, 2009.

6. Wang Y, Zhang ZZ, Wu Y, Zhan J, He XH and Wang YL: Honokiol protects rat hearts against myocardial ischemia reperfusion injury by reducing oxidative stress and inflammation. Exp Ther Med 5: 315-319, 2013

7. Mishra PK, Tyagi N, Kundu S and Tyagi SC: MicroRNAs are involved in homocysteine-induced cardiac remodeling. Cell Biochem Biophys 55: 153-162, 2009.

8. Liu F, Yin L, Zhang L, Liu W, Liu J, Wang Y and Yu B: Trimetazidine improves right ventricular function by increasing miR-21 expression. Int J Mol Med 30: 849-855, 2012.

9. Ikeda $\mathrm{S}$ and $\mathrm{Pu}$ WT: Expression and function of microRNAs in heart disease. Curr Drug Targets 11: 913-925, 2010.

10. Opie LH and Boucher F: Trimetazidine and myocardial ischemic contracture in isolated rat heart. Am J Cardiol 76: 38B-40B, 1995.

11. Kim JS, Kim CH, Chun KJ, Kim JH, Park YH, Kim J, Choi JH, Lee SH, Kim EJ, Yu DG, et al: Effects of trimetazidine in patients with acute myocardial infarction: Data from the Korean acute myocardial infarction registry. Clin Res Cardiol 102: 915-922, 2013

12. Hoda MN, Li W, Ahmad A, Ogbi S, Zemskova MA, Johnson MH, Ergul A, Hill WD, Hess DC and Sazonova IY: Sex-independent neuroprotection with minocycline after experimental thromboembolic stroke. Exp Transl Stroke Med 3: 16, 2011.

13. Hoda MN, Siddiqui S, Herberg S, Periyasamy-Thandavan S Bhatia K, Hafez SS, Johnson MH, Hill WD, Ergul A, Fagan SC and Hess DC: Remote ischemic perconditioning is effective alone and in combination with intravenous tissue-type plasminogen activator in murine model of embolic stroke. Stroke 43: 2794-2799, 2012.
14. Livak KJ and Schmittgen TD: Analysis of relative gene expression data using real-time quantitative PCR and the 2(-Delta Delta C(T)) Method. Methods 25: 402-408, 2001.

15. Li X, Liu J, Lin L, Guo Y, Lin C, Zhang C and Yang B Traditional Chinese medicine shuang shen ning xin attenuates myocardial ischemia/reperfusion injury by preserving of mitochondrial function. Evid Based Complement Alternat Med 2014: 180965, 2014

16. Qiao Z, Ma J and Liu H: Evaluation of the antioxidant potential of Salvia miltiorrhiza ethanol extract in a rat model of ischemia-reperfusion injury. Molecules 16: 10002-10012, 2011.

17. Shen B, Li J, Gao L, Zhang J and Yang B: Role of CC-chemokine receptor 5 on myocardial ischemia-reperfusion injury in rats. Mol Cell Biochem 378: 137-144, 2013.

18. Ussher JR, Fillmore N, Keung W, Mori J, Beker DL, Wagg CS, Jaswal JS and Lopaschuk GD: Trimetazidine therapy prevents obesity-induced cardiomyopathy in mice. Can J Cardiol 30: 940-944, 2014

19. Allibardi S, Chierchia SL, Margonato V, Merati G, Neri G, Dell'Antonio G and Samaja M: Effects of trimetazidine on metabolic and functional recovery of postischemic rat hearts. Cardiovasc Drugs Ther 12: 543-549, 1998.

20. Zhou J and Zhang J: Identification of miRNA-21 and miRNA-24 in plasma as potential early stage markers of acute cerebral infarction. Mol Med Rep 10: 971-976, 2014.

21. Duan X, Ji B, Wang X, Liu J, Zheng Z, Long C, Tang Y and $\mathrm{Hu}$ S: Expression of microRNA-1 and microRNA-21 in different protocols of ischemic conditioning in an isolated rat heart model. Cardiology 122: 36-43, 2012.

22. Yin C, Wang $X$ and Kukreja RC: Endogenous microRNAs induced by heat-shock reduce myocardial infarction following ischemia-reperfusion in mice. FEBS Lett 582: 4137-4142, 2008.

23. Damania P, Sen B, Dar SB, Kumar S, Kumari A, Gupta E, Sarin SK and Venugopal SK: Hepatitis B virus induces cell proliferation via HBx-induced microRNA-21 in hepatocellular carcinoma by targeting programmed cell death protein 4 (PDCD4) and phosphatase and tensin homologue (PTEN). PLoS One 9: e91745, 2014.

24. Jansen F, Yang X, Proebsting S, Hoelscher M, Przybilla D, Baumann K, Schmitz T, Dolf A, Endl E, Franklin BS, et al: MicroRNA expression in circulating microvesicles predicts cardiovascular events in patients with coronary artery disease. J Am Heart Assoc 3: e001249, 2014.

25. Song JQ, Teng X, Cai Y, Tang CS and Qi YF: Activation of Akt/GSK-3beta signaling pathway is involved in intermedin(1-53) protection against myocardial apoptosis induced by ischemia/reperfusion. Apoptosis 14: 1299-1307, 2009.

26. Zhang XJ, Xiong ZB, Tang AL, Ma H, Ma YD, Wu JG and Dong YG: Rosiglitazone-induced myocardial protection against ischaemia-reperfusion injury is mediated via a phosphatidylinositol 3-kinase/Akt-dependent pathway. Clin Exp Pharmacol Physiol 37: 156-161, 2010.

27. Kutala VK, Khan M, Mandal R, Ganesan LP, Tridandapani S, Kalai T, Hideg K and Kuppusamy P: Attenuation of myocardial ischemia-reperfusion injury by trimetazidine derivatives functionalized with antioxidant properties. J Pharmacol Exp Ther 317: 921-928, 2006.

28. Liu Z, Li Z and Liu X: Effect of ginsenoside Re on cardiomyocyte apoptosis and expression of $\mathrm{Bcl}-2 / \mathrm{Bax}$ gene after ischemia and reperfusion in rats. J Huazhong Univ Sci Technolog Med Sci 22: 305-309, 2002.

29. Tian Y, Zhang W, Xia D, Modi P, Liang D and Wei M: Postconditioning inhibits myocardial apoptosis during prolonged reperfusion via a JAK2-STAT3-Bcl-2 pathway. J Biomed Sci 18: 53, 2011.

30. Khan M, Meduru S, Mostafa M, Khan S, Hideg K and Kuppusamy P: Trimetazidine, administered at the onset of reperfusion, ameliorates myocardial dysfunction and injury by activation of $\mathrm{p} 38$ mitogen-activated protein kinase and Akt signaling. J Pharmacol Exp Ther 333: 421-429, 2010. 